\title{
Phenotypic and Genotypic Study of Antibiotic Resistance among Escherichia coli Isolates from Human Urinary Infection Cases in Bojnord Province
}

\author{
Mohadese Amiri', Hamidreza Farzin², Majid Jamshidian-Mojaver², \\ ${ }^{1}$ MSc in Bacteriology, School of Veterinary Medicine, Shahid Bahonar University of Kerman, Kerman, Iran \\ ${ }^{2}$ Assistant Professor-Mashhad Branch, Razi Vaccine and Serum Research Institute, Agricultural Research, Education and \\ Extension Organization (AREEO), Mashhad, Iran
}

* Corresponding Author: Majid Jamshidian-Mojaver, Razi Vaccine and Serum Research Institute, Agricultural Research, Education and Extension Organization (AREEO), Mashhad, Iran.Email: mjmojaver@yahoo.com

\begin{tabular}{|c|c|}
\hline & Abstract \\
\hline $\begin{array}{l}\text { Received: } 19.08 .2019 \\
\text { Accepted: } 17.11 .2019\end{array}$ & \multirow[b]{2}{*}{$\begin{array}{l}\text { Background and Objective: Bacterial agents are the most common causes } \\
\text { of urinary infection with Escherichia coli as the major causative organism. } \\
\text { Accordingly, the current study aimed to determine the antibiotic resistance } \\
\text { among Escherichia coli isolates from human urinary infection cases. } \\
\text { Materials and Methods: The current experimental study was carried out on } \\
50 \text { specimens of positive cultures with urinary tract infection referred to } \\
\text { Imam Reza Hospital Laboratory in Bojnord, Iran. The resistance and } \\
\text { susceptibility of the isolates were assessed using disc diffusion method. } \\
\text { Moreover, the presence of tetA, blaTEM, Sull, aac(3)-IV, and aadAl gens } \\
\text { was examined using molecular methods with specific primers. } \\
\text { Results: Prevalence of antibiotic resistance to ampicillin, cotrimaxazole, } \\
\text { levofloxacin, nalidixic acid, ciprofloxacin, gentamicin, and nitrofurantoin } \\
\text { was measured at } 84 \%, 60 \%, 60 \%, 52 \%, 44 \%, 22 \% \text {, and } 6 \% \text {, respectively. in } \\
\text { total, } 50 \text { E. coli strains were isolated were examined to determine blaTEM, } \\
\text { aac(3)-IV, tetA, Sul, and aadA1 genes using polymerase chain } \\
\text { reaction(PCR). Based on the obtained results, the frequency of blaTEM, } \\
\text { aac(3)-IV, tetA, Sull, aac(3)-IV, and aadA1 genes was reported as } 24 \% \text {, } \\
12 \%, 10 \%, 8 \% \text {, and } 14 \% \text {, respectively. } \\
\text { Conclusion: Disk diffusion agar method can be used as a primary screening } \\
\text { method to determine antibiotic susceptibility for Escherichia coli isolates } \\
\text { separated from urinary tract infections. In addition, genotypic method can be } \\
\text { implemented for the accurate evaluation of the resistance of the isolates. }\end{array}$} \\
\hline $\begin{array}{l}\text { How to Cite this Article: } \\
\text { Amiri M, Farzin H, Jamshidian- } \\
\text { Mojaver M. Phenotypic and } \\
\text { Genotypic Study of Antibiotic } \\
\text { Resistance among Escherichia } \\
\text { coli Isolates from Human Urinary } \\
\text { Infection Cases in Bojnord } \\
\text { Province. Avicenna J Clin Med. } \\
\text { 2019; 26(3): 173-180. DOI: } \\
\text { 10.29252/ajcm.26.3.173 }\end{array}$ & \\
\hline & \\
\hline
\end{tabular}


dof: $10.29252 / \mathrm{ajcm} \cdot 26.3 .173$

\section{بررسى فنوتيى و زنوتيّى مقاومت آنتىبيوتيكى در جدايههاى اشريشياكلى از موارد عفونتهاى ادرارى در شهر ستان بجنورد}

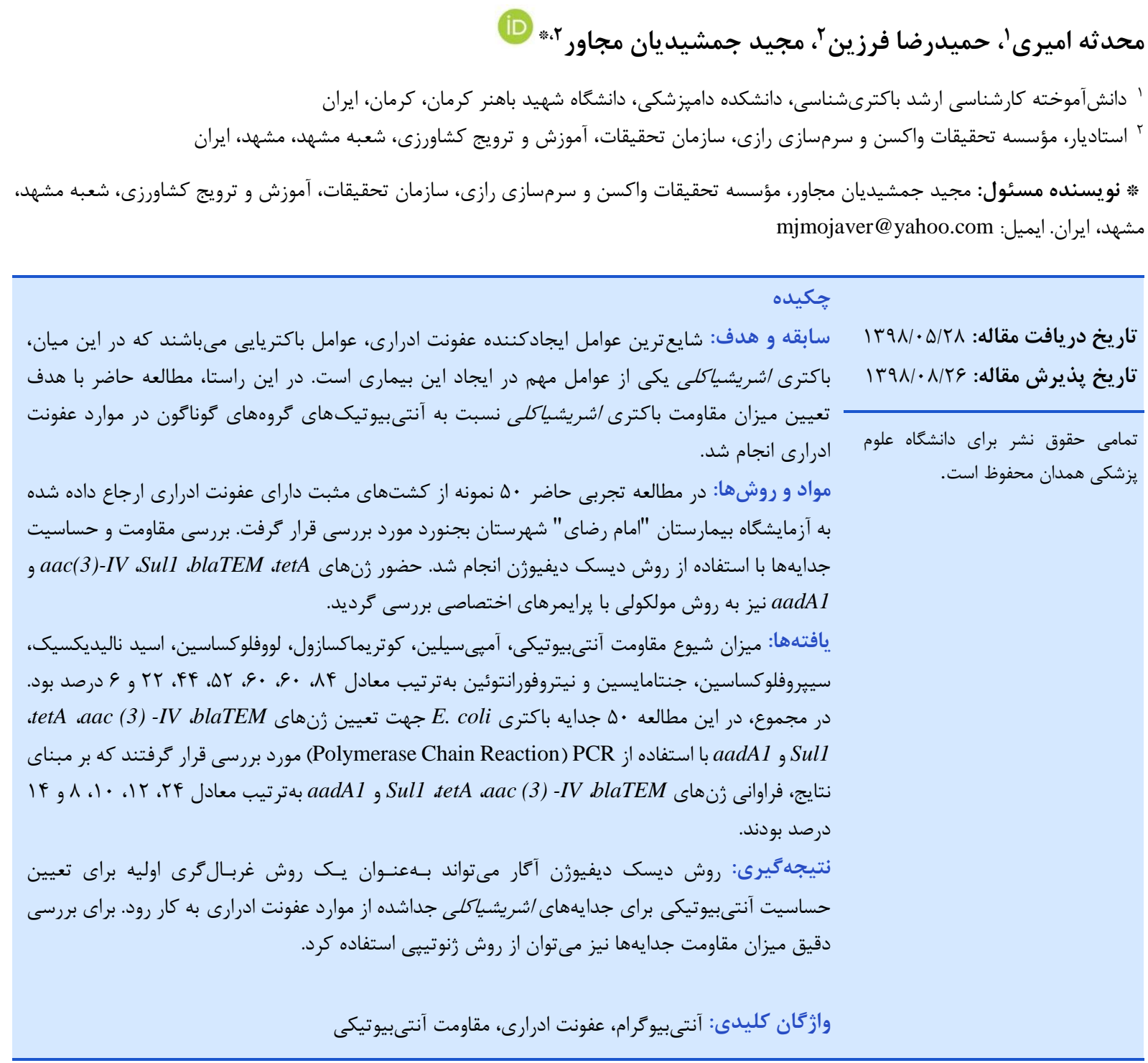

مقلدمه

[ب]. آكَاهى از الكَوى مقاومت آنتىبيوتيكى نقش مهمى را در

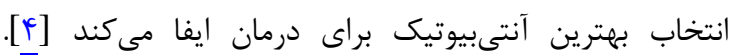

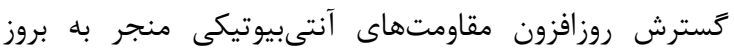

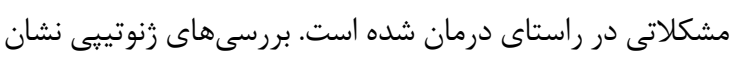

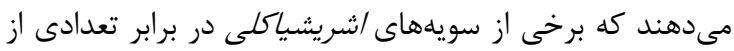

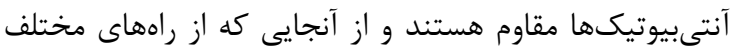

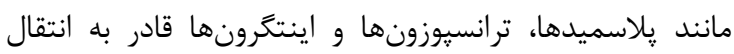
عوامل زنتيكى مقاومت به سويههاى ديخر مى باشند، شاهد افزايش

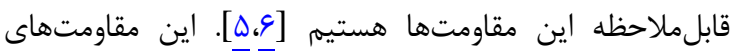

عفونت ادرارى يكى از شايعترين عفونتهاى باكتريايى مىباشد و هر ساله • ل1 ميليون نفر در سراسر دنيا با اين عفونت درگير مىباشند [1].

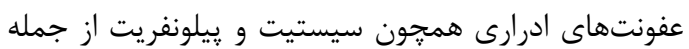
عفونتهاى شايع در جوامع و بيمارستانها هستند و باكترى

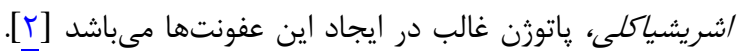

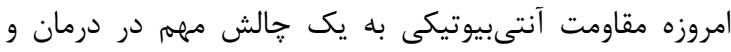
كنترل بيمارىهاى عفونى (عفونت ادرارى) تبديل شده است و

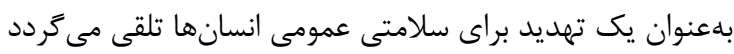


تعيين ميزان حساسيت و مقاومت آنتسىبيوتيكسى جدايه هاى

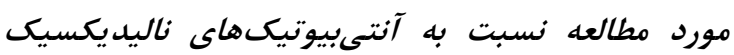

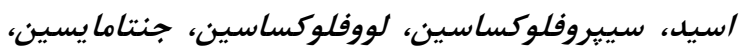
كوتريماكسازول، آميىسيلين و نيتروفورانتوئين

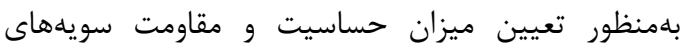

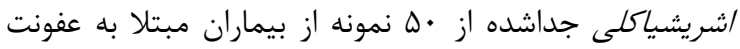

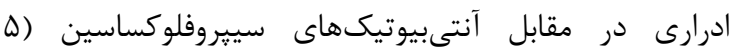

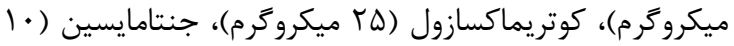

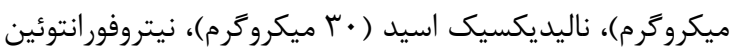

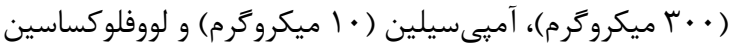

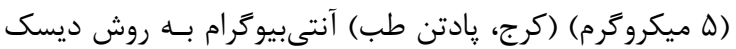

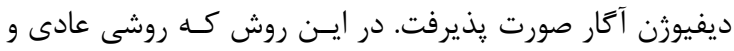

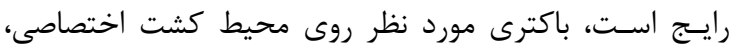

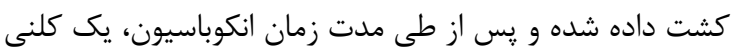

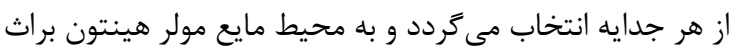

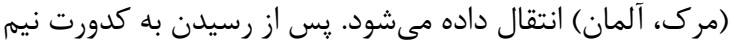

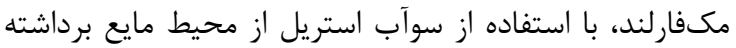

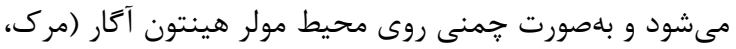

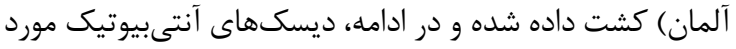

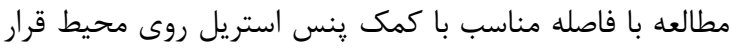

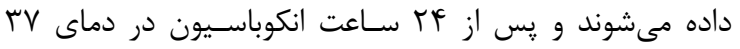

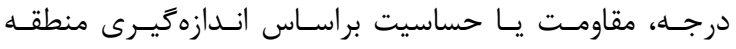
CLSI عـدم رشـد بررسى كرديده و نتايج آن با كمك جدول

بررسى مىشود [1 اI]

استخراج DNA

براى استخراج DNA از روش جوشاندن استفاده كرديد [با].

\section{روش PCR جهت رديابى زنهاى Sul1 blaTEM tetA $\operatorname{aac}(3)-I V$ gaadA1}

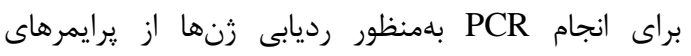

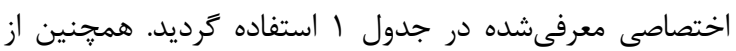

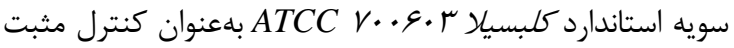

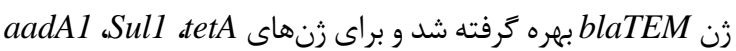

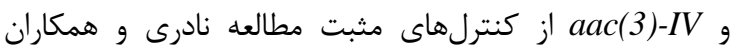
استفاده كرديد. از آب ديونيزه نيز بهعنوان كنترل منترل منفى استفاده

جدول ا: توالى يرايمرهاى مورد استفاده براى رديابى زنها

\begin{tabular}{|c|c|c|}
\hline منبع & اندازه محصول (bp) & 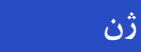 \\
\hline [10] & $\Delta \cdot T$ & tetA \\
\hline$[10]$ & TFV & blaTEM \\
\hline [19] & Frr & Sul1 \\
\hline [IV] & FqV & aadA1 \\
\hline [1ᄉ] & rAS & $\operatorname{aac}(3)-I V$ \\
\hline
\end{tabular}

آنتىبيوتيكى در حيوانات از طريق گوشت يا ديكر محصولات وارد

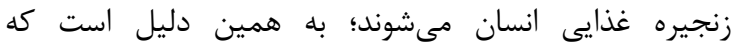
مقاومتهاى آنتىبيوتيكى، تهديدى براى سلاني سلامت انسان و حيوان

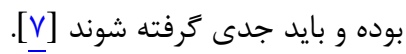

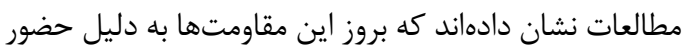

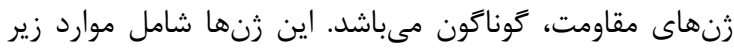

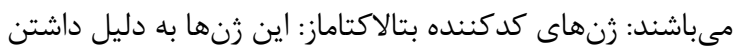

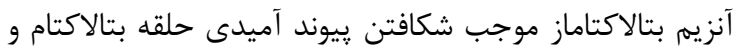

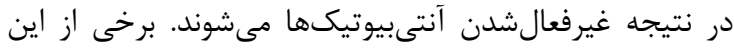
زن ها عبارت هستند از: bla bla bla

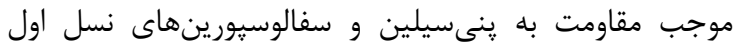

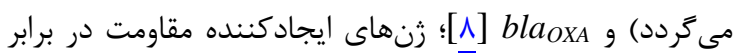

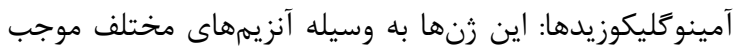

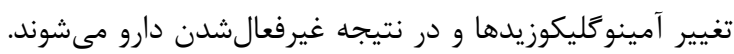
تعدادى از اين زنها عبارت هستند ازي: aadAl (به وسيله

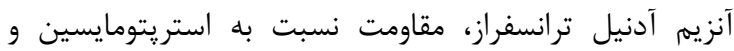

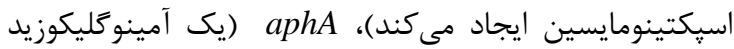

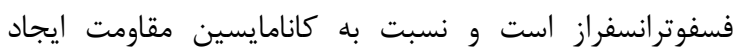

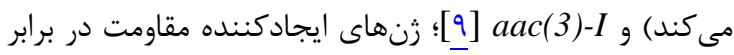

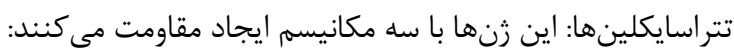

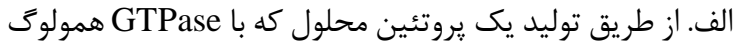
است، از ريبوزوم باكترىها در برابر تتراسايكلين محافظت

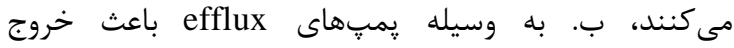
آنتىبيوتيكها و كاهش غلظت آنها دئ در سلول مىشوند، ج.

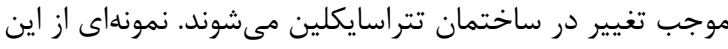

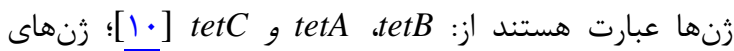

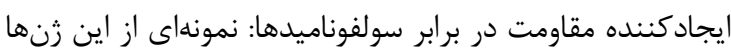

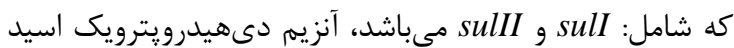

سنتاز را مهار مى كند [111] با توجه به اهميت موارد ذكر شده، مطالعه حاضر با هدف تعيدين

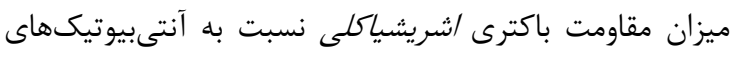
كروههاى كوناكون در موارد عفونت ادرارى انجام شد.

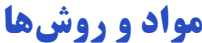
در مطالعه تجربى حاضر •ه نمونه از كشتهاى مثبت داراى

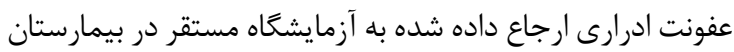

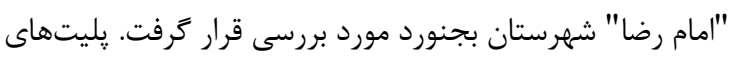

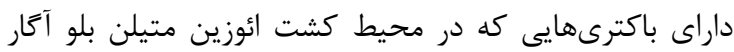

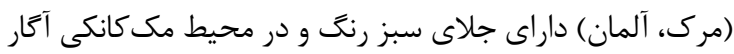

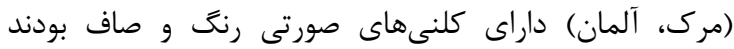

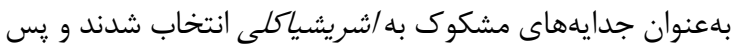
از تأييد توسط آزمايشهاى بيوشيميايى نظير آزمون اوره، سيمون بـاني

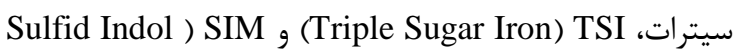
Motility 
آنتىبيوتيكى بودند كه از بين آنها FF درصد (T ا ايزوله) داراى

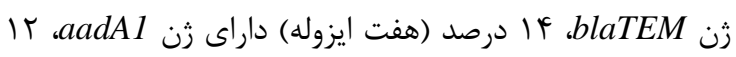

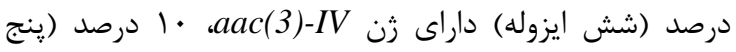

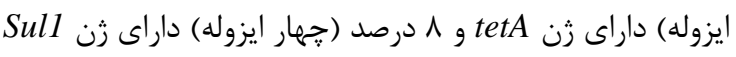

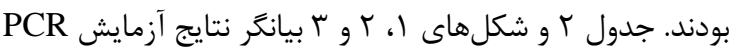

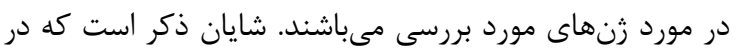

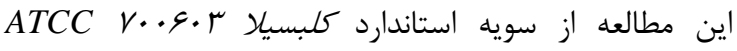

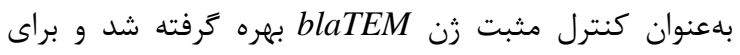

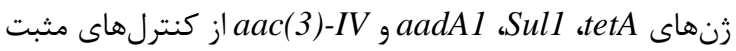
مطالعه نادرى و همكاران استفاده گرديد. از آب ديونيزه نيز

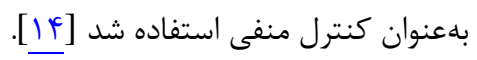

جدول r: فراوانى زنهاى مورد مطالعه

\begin{tabular}{|c|c|c|}
\hline درصد فراوانى & 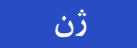 & عوامل آنتىميكروبيال \\
\hline $1 \cdot$ & tetA & Oxytetracycline \\
\hline TF & blaTEM & $\beta$-Lactamase \\
\hline$\wedge$ & Sull & Sulfonamide \\
\hline If & aadA1 & Streptomycin \\
\hline ir & $\operatorname{aac}(3)-I V$ & Gentamicin \\
\hline
\end{tabular}

شد [1 [1 [

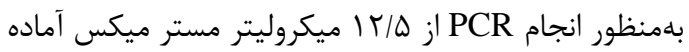
BIOFACT)

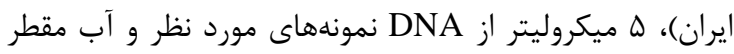

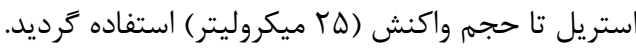

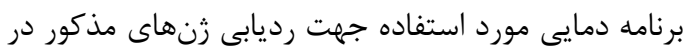

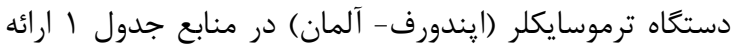

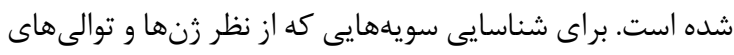

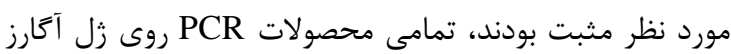

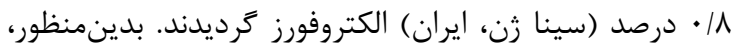

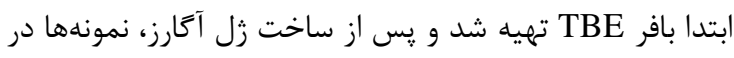

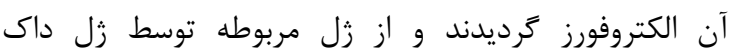
عكسبردارى شد و مورد بررسى قرار (Optigo ISOGENE)

\section{كافته انها}

نتيجه آزمايش PCR براى شناسايى ثنهاى tetA Sul1 gaac(3)-IV aadA1 blaTEM از ميان ••ه جدايه مورد بررسى، ؟F جدايه داراى زن مقاومت

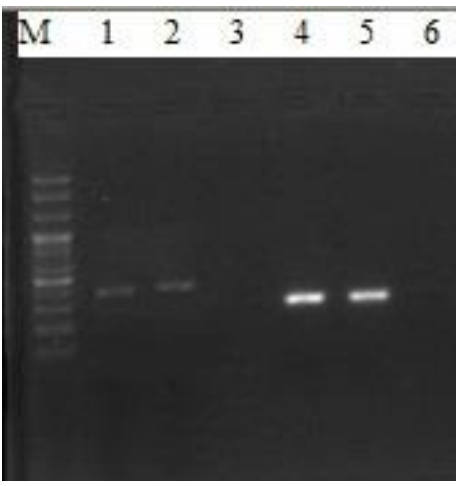

شكل ا: نتيجه آزمايش PCR براى شناسايى زنهاى

M: lad 1... bp (BIOFACT-Korea)

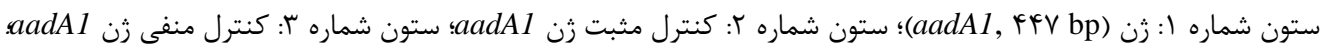

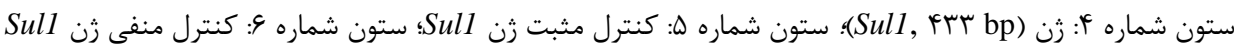

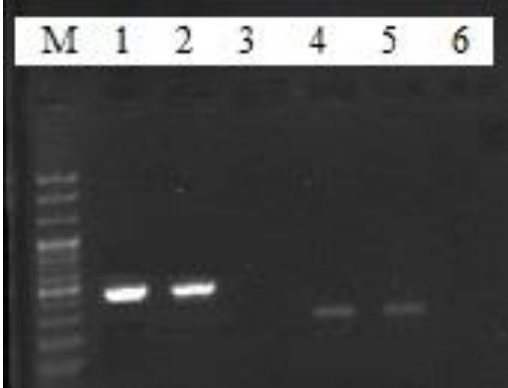

aac(3)-IV tetA براى شناسايى ثنهاى PCR شكل r: نتيجه آزمايش

M: lad 1... bp (BIOFACT-Korea)

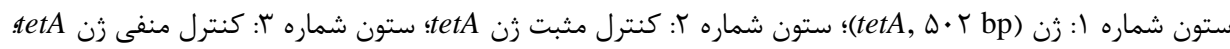

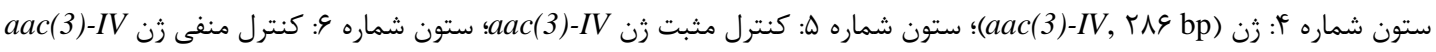




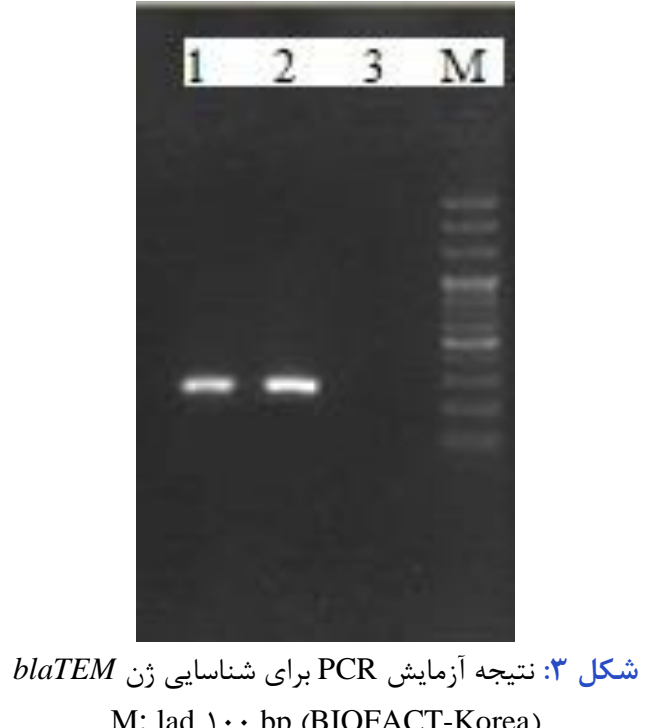

ستون شماره ا: زن (blaTEM, rFv bp)؛ ستون شماره r: كنترل مثبت زن blaTEM ستون شماره ऍ: كنترل منفى زن blaTEM

جدول ب: فراوانى مقاومت و حساسيت جدايهها در برابر آنتىبيوتيكهاى مورد مطالعه

\begin{tabular}{|c|c|c|c|}
\hline مقاوم & نيمه حساس & حساس & آنتى بيوتيك \\
\hline r & 11 درصد & 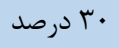 & ناليديكسيك اسيد \\
\hline FF & عا درصد & F. F درصد & سييروفلوكساسين \\
\hline أع درصد & 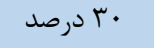 & • ا درصد & لووفلوكساسين \\
\hline r T درصد & • درصد & ل درصد V^ & جنتامايسين \\
\hline ع ع درصد. & r درصد & גץ درصد & كوتر يماكسازول \\
\hline 9 & • درصد & F & نيتروفورانتوئين \\
\hline F & ع درصد & . ا درصد & آميىسيلين \\
\hline
\end{tabular}

جنتامايسين و نيتروفورانتوئين مورد بررسى قرار كرفت. نتايج

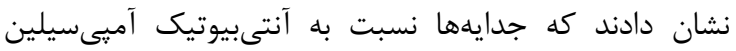

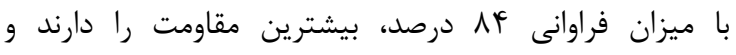

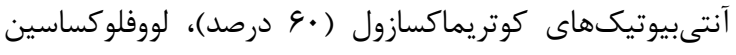

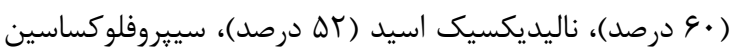

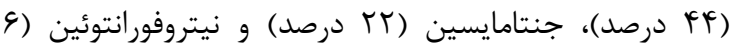
درصد) در رتبههاى بعد از آن قرار داشتند. در اين مطالعه ميزان

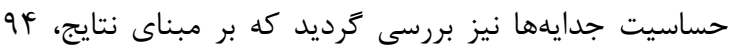

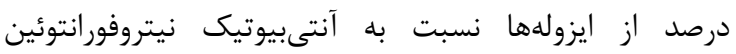

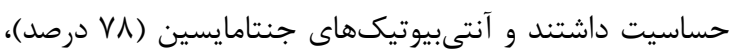

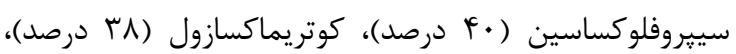

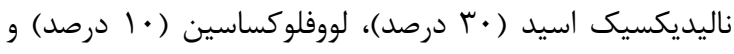

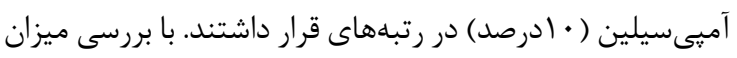
مقاومت به روش زنوتييى نيز مشخص شد كه بيشترين رين مين ميزان

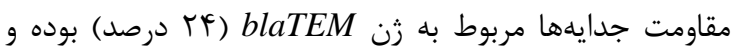
زن هاى aadA1

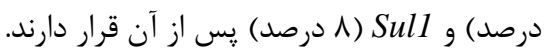

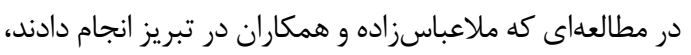

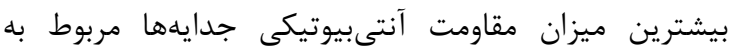

مورد مطاليج ميزان حساسيت و مقاومت آنتسبيوتيكسى جدا يههاى نتايج بهدستآمده از اين مطالعه نشان دادند كه بيشترين

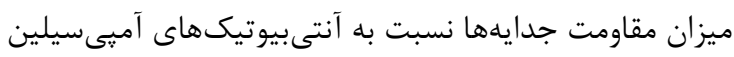

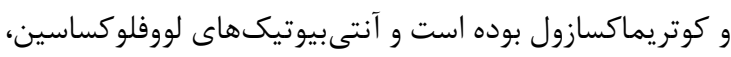

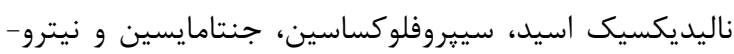

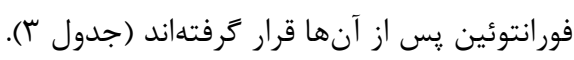

عفونتهاى ادرارى يكى از عفونتهاى شايع و رايجى هستند

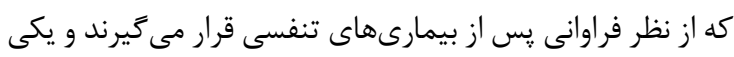

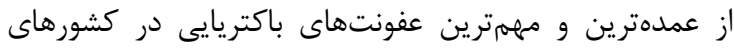

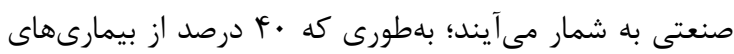

عفونى بيمارستانى را عفونت ادرارى تشكيل مى دهد [19.19.

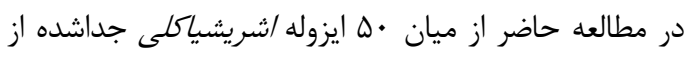

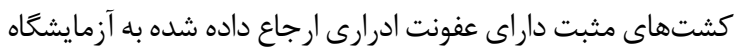

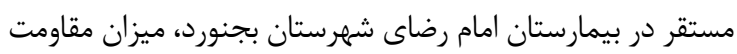

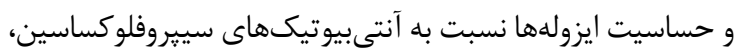

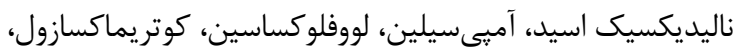


آنتىبيوتيكى مربوط به آميىسيلين (NV درصد) بود [بY] نتايج اين مطالعه با يافتههاى مطالعه حاضر مشابه مىبـاشد.

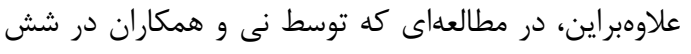

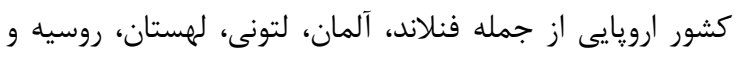

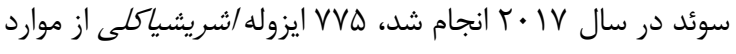

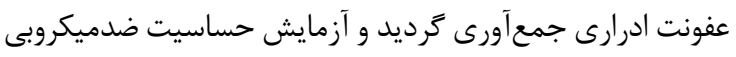

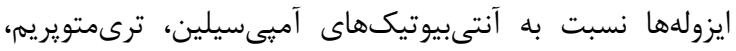

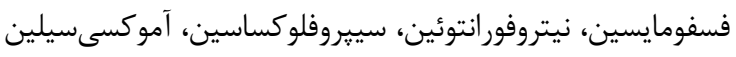

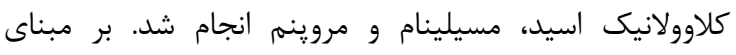

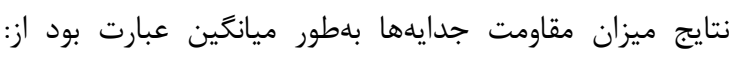

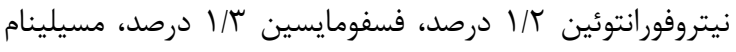

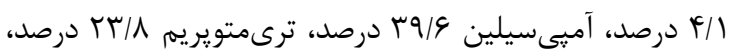

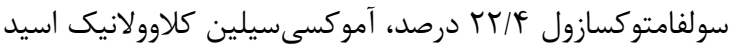

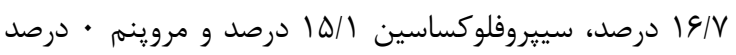

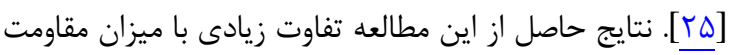

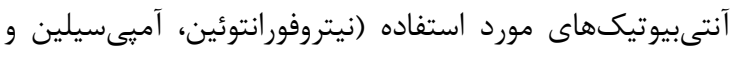

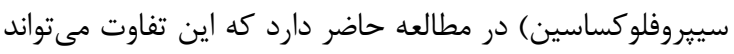

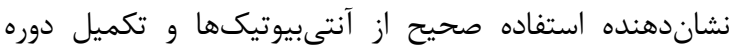
درمانى آنها از سوى بيماران در كشورهاى ارويايى باشد.

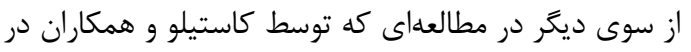

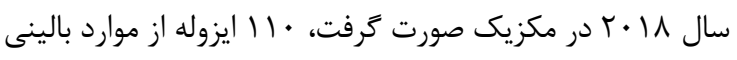

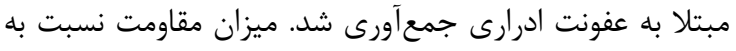

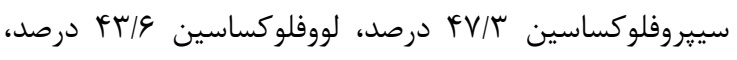

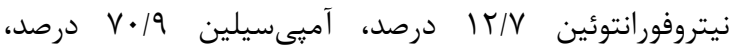

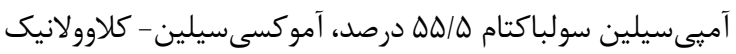

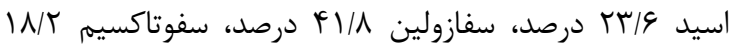

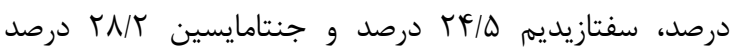
كزارش شد [عب]. نتايج حاصل از اين مطالعه در مورد ميزان

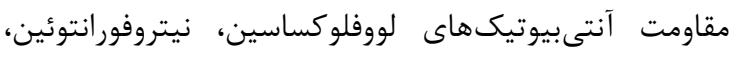

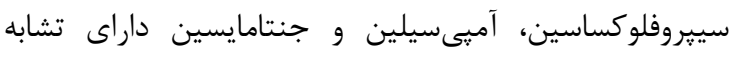
تقريبى با يافتههاى مطالعه حاضر مىباشد.

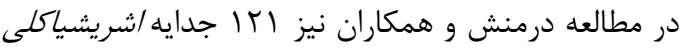

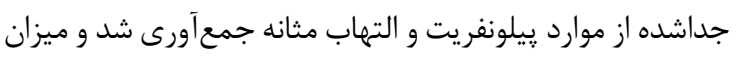
مقاومت جدايهها بلصورت زنوتييى در ارتباط با جدايهها بررسى دئوسي

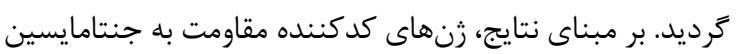

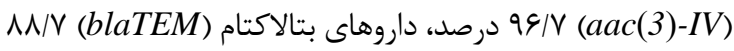

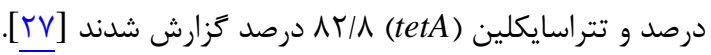

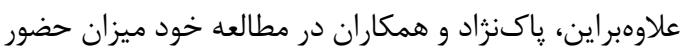

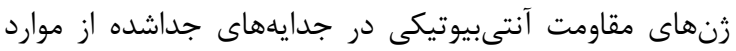
عفونت ادرارى شامل: زنهاى ctetA،

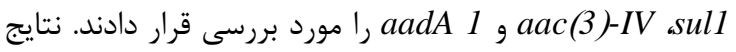

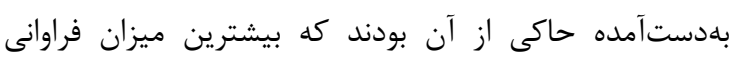

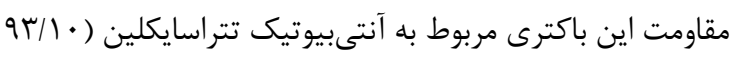

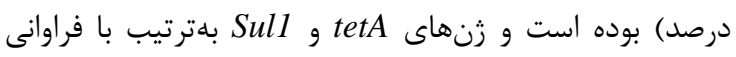

آنتىبيوتيكهاى آميىسيلين به ميزان ه/ N د درصد، جنتامايسين

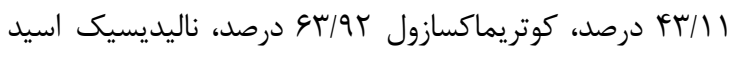
د د

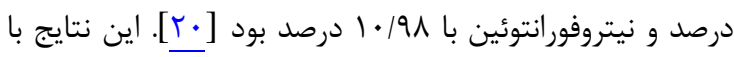

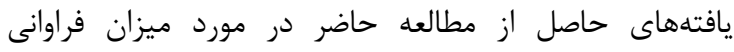

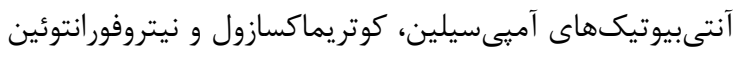
اختلاف اندكى دارد؛ اما اين اختلاف در مورد ميزان فراوانى

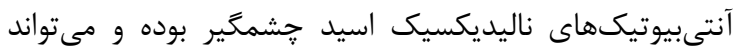

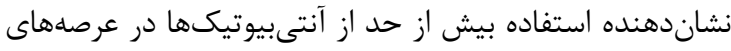
يزشكى و يا در توليدات مواد غذايى باشد.

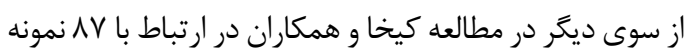

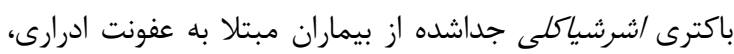

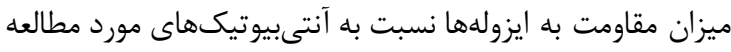

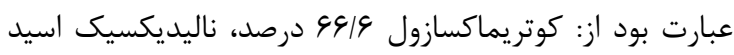

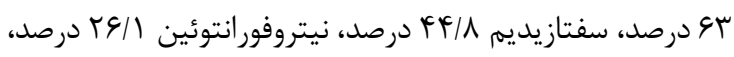

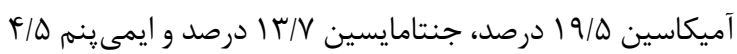

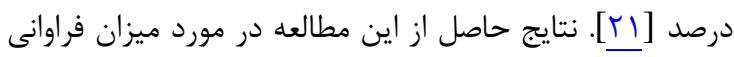

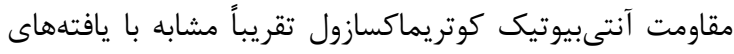

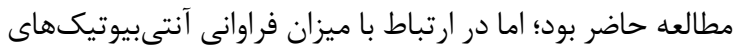

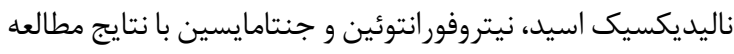
حاضر اختلاف داشت كه اين اختلاف مى تواند نشاندهنده مصرئن

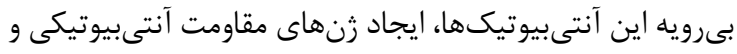

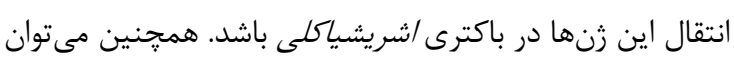

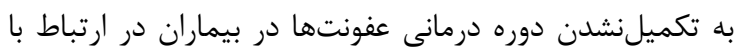
مقاومت ايجادشده اشاره نمود.

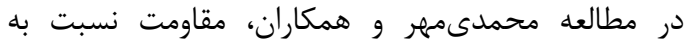

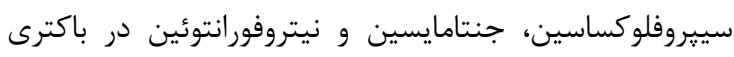

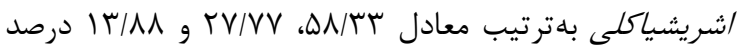

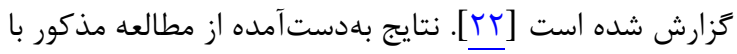

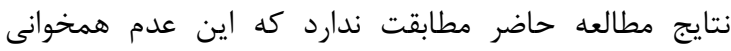
مى تواند نشاندهنده عدم اطلاعات كافى مردم در مورد نحاض نحوه

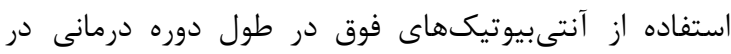
بيمارى هاى عفونى باشد. از سوى ديخر در مطالعه شريفى يزدى و همكاران كه در شهر خوى صورت كرفت، ميزان مقاومت به كوتريماكسازول معادل

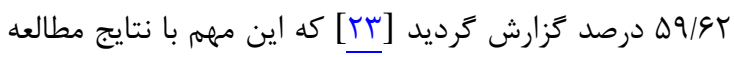
حاضر تقريباً داراى تطابق مىباشد (اين ميزان در مطالعه حاضر

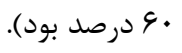

سوادكوهى برارى و همكاران نيز در مطالعه خود ميزان

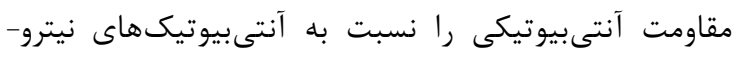

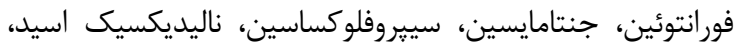
كوتريماكسازول، آميى سيلين، سفكسيم و سفالكسين را را در ارتباط سئين

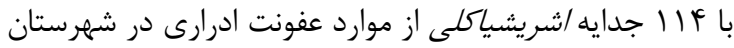

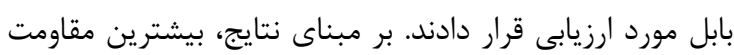


انجام آزمايشات مقاومت آنتىبيوتيكى در آزمايشگاهها لازم و ضرورى مى باشد. تشكر و قلر دانى

بدينوسيله نويسندكان از كاركنان آزمايشعاه تحقيقات

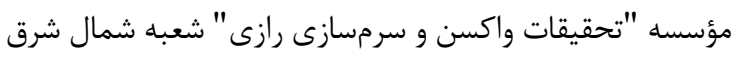

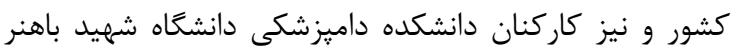

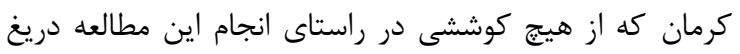
ننمودند، تشكر و قدردانى مئنمايند.

تضاد منافع

بين نويسندَان و نتايج اين مطالعه هيجَّونه تعارض منافعى

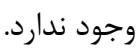

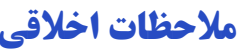

مطالعه حاضر در تكميل پِايانامه كارشناسى ارشد

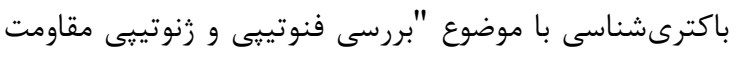
نسبت به فلوركينولونها در جدايههاى /شريشياكلى از موضى موارد عفونتهاى ادرارى در شهرستان بجنورد" مصوب دانشعاه شهيد

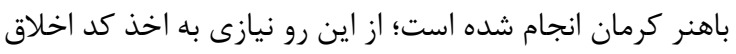

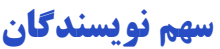

نويسنده اول (يزوهشكر اصلى) تدوين بخشهاى مقدمده،

نتايج، روششناسى و كمك در نتارش مقاله (بس درصد)،

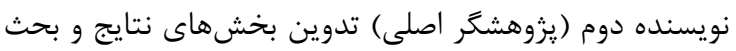

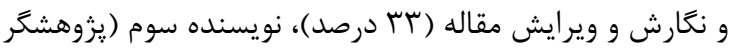
اصلى) تدوين بخشهاى نتايج و بحث و نعارش و ويرايش مقاله

\section{حمايت مالَى}

مطالعه حاضر از سوى مؤسسه تحقيقات واكسن و سرمسازى

$$
\text { مشهد يشتيبانى مالى شده است. }
$$

\section{REFERENCES}

1. Foxman B. Urinary tract infection syndromes: occurrence, recurrence, bacteriology, risk factors, and disease burden. Infect Dis Clin North Am. 2014;28(1):1-13. PMID: 24484571 DOI: $10.1016 /$ j.idc.2013.09.003

2. Ronald AR, Nicolle LE, Stamm E, Krieger J, Warren J, Schaeffer A, et al. Urinary tract infection in adults research priorities and strategies. Int J Antimicrob Agents. 2001; 17(4):343-8. PMID: 11295419 DOI: $10.1016 /$ s09248579(01)00303-X

3. Amiri M, Jajarmi M, Ghanbarpour R. Prevalence of resistance to quinolone and fluoroquinolone antibiotics and screening of $q n r$ genes among Escherichia coli isolates from urinary tract infection. Int J Enteric Pathog. 2017;5(4):1005. DOI: 10.15171/ijep.2017.24

4. Trabulsi LR, Keller R, Tardelli Gomes TA. Typical and atypical enteropathogenic Escherichia coli. Emerg Infect Dis. 2002;8(5):508-13. PMID: 11996687 DOI: 10.3201/eid0805.
VD/AC بايد خاطرنشان ساخت كه يافتههاى مطالعه حاضر در مقرئ مقايسه

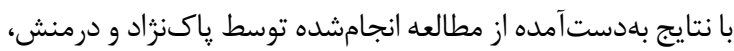

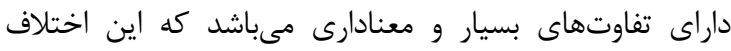

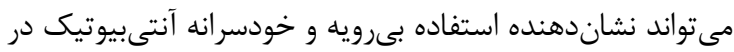
موارد بيمارىهاى عفونى از جمله عفونت ادرارى باشد.

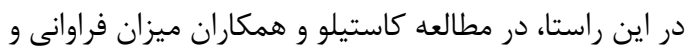

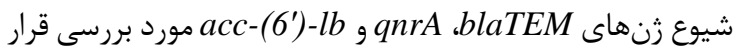

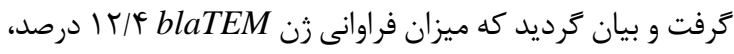

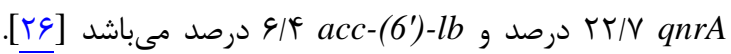
ميزان فراوانى زن blaTEM در اين مطالعه نسبت به مطالعه

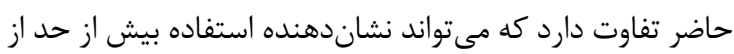

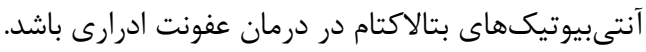

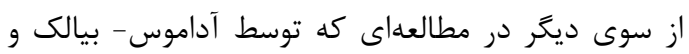

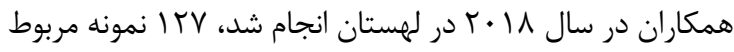

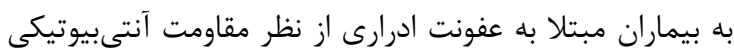
نسبت به زنهاى بتا-لاكتاماز (blaTEM)، آمينوگليكوزيدها

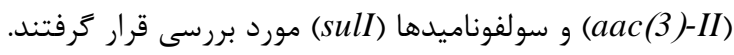

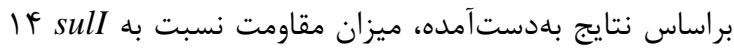

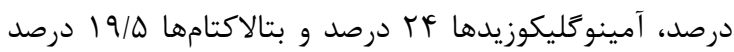

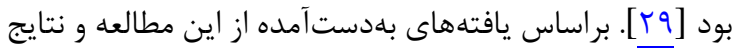

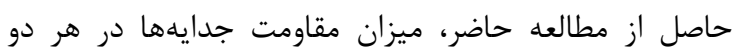
مطالعه مشابه مىباشد.

نتايج حاصل از اين مطالعه نشان دادند كه روش ديسك

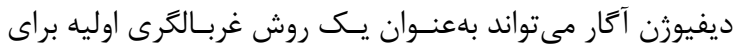

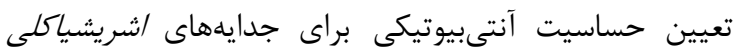

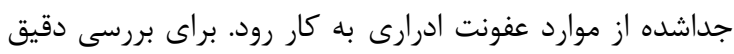

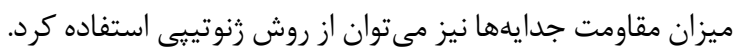

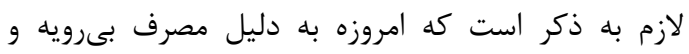

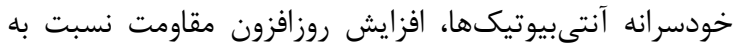

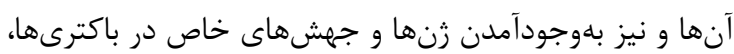

$\underline{010385}$

5. Davis MA, Besser TE, Orfe LH, Baker KN, Lanier AS, Broschat SL, et al. Genotypic-phenotypic discrepancies between antibiotic resistance characteristics of Escherichia coli isolates from calves in management settings with high and low antibiotic use. Appl Environ Microbiol. 2011; 77(10):3293-9. PMID: 21421795 DOI: 10.1128/AEM. 02588-10

6. Lee JC, Oh JY, Cho JW, Park JC, Kim JM, Seol SY, et al. The prevalence of trimethoprim-resistance-conferring dihydrofolate reductase genes in urinary isolates of Escherichia coli in Korea. $J$ Antimicrob Chemother. 2001;47(5):599-604. PMID: 11328770 DOI: $10.1093 / \mathrm{jac} /$ 47.5.599

7. Ghanbarpour R, Daneshdoost S. Identification of shiga toxin and intimin coding genes in Escherichia coli isolates from pigeons (Columba livia) in relation to phylotypes and 
antibiotic resistance patterns. Trop Anim Health Prod. 2012;44(2):307-12. PMID: 22105907 DOI: 10.1007/s11250011-0021-0

8. Colom K, Pérez J, Alonso R, Fernández-Aranguiz A, Lariño E, Cisterna R. Simple and reliable multiplex PCR assay for detection of bla $a_{T E M}$, bla $a_{S H V}$ and bla $a_{O X A-1}$ genes in Enterobacteriaceae. FEMS Microbiol Lett. 2003;223(2):14751. PMID: 12829279 DOI: 10.1016/S0378-1097(03)00306-9

9. Randall LP, Cooles SW, Osborn MK, Piddock LJ, Woodward MJ. Antibiotic resistance genes, integrons and multiple antibiotic resistance in thirty-five serotypes of Salmonella enteric isolated from humans and animals in the UK. $J$ Antimicrob Chemother. 2004;53(2):208-16. PMID: 14729766 DOI: $10.1093 / \mathrm{jac} / \mathrm{dkh} 070$

10. Lin CH, Hou RF, Shyu CL, Shia WY, Lin CF, Tu WC. In vitro activity of mastoparan-AF alone and in combination with clinically used antibiotics against multiple-antibioticresistant Escherichia coli isolates from animals. Peptides. 2012;36(1):114-20. PMID: 22561066 DOI: 10.1016/j. peptides.2012.03.002

11. Antunes P, Machado J, Sousa JC, Peixe L. Dissemination of sulfonamide resistance genes (sul1, sul2, and sul3) in Portuguese Salmonella enteric Strains and Relation with Integrons. Antimicrob Agents Chemother. 2005;49(2):836-9. PMID: 15673783 DOI: $10.1128 / A A C$.49.2.836-839.2005

12. Clinical and Laboratory Standards Institute. Performance standards for antimicrobial susceptibility testing: twentysecond informational supplement. CLSI document M100S22. Wayne, PA, USA: Clinical and Laboratory Standards Institute; 2016

13. Askari Badouei M, Jajarmi M, Mirsalehian A. Virulence profiling and genetic relatedness of Shiga toxin-producing Escherichia coli isolated from humans and ruminants. Comp Immunol Microbiol Infect Dis. 2015;38:15-20. PMID: 25534186 DOI: $10.1016 /$ j.cimid.2014.11.005

14. Naderi Z, Ghanbarpour R, Sami M. Antimicrobial resistance characteristics and phylogenetic groups of Escherichia coli isolated from diarrheic calves in southeast of Iran. Int J Enteric Pathog. 2016;4(4):537-48. DOI: 10.15171/ijep.2016.15

15. Kozak G, Boerlin P, Janecko N, Jardine C. Antimicrobial resistance in Escherichia coli isolates from swine and wild small mammals in the proximity of swine farms and in natural environments in Ontario, Canada. Appl Environ Microbiol. 2009;75(3):559-66. PMID: 19047381 DOI: 10.1128/AEM. 01821-08

16. Kerrn MB, Klemmensen T, Frimodt-Møller N, Espersen F. Susceptibility of Danish Escherichia coli strains isolated from urinary tract infections and bacteraemia, and distribution of sul genes conferring ulphonamide resistance. J Antimicrob Chemother. 2002;50(4):513-6. PMID: 12356795 DOI: $10.1093 / \mathrm{jac} / \mathrm{dkf164}$

17. Machado E, Coque TM, Canton R, Novais A, Sousa JC, Baquero F, et al. High diversity of extended-spectrum betalactamases among clinical isolates of Enterobacteriaceae from Portugal. J Antimicrob Chemother. 2007;60(6):1370-4. PMID: 17913717 DOI: $10.1093 / \mathrm{jac} / \mathrm{dkm} 381$

18. Van TT, Chin J, Chapman T, Tran LT, Coloe PJ. Safety of raw meat and shellfish in Vietnam: an analysis of Escherichia coli isolations for antibiotic resistance and virulence genes. Int J Food Microbiol. 2008;124(3):217-23. PMID: 18457892
DOI: 10.1016/j.ijfoodmicro.2008.03.029

19. Podschun R, Ullmann U. Klebsiella spp. As nosocomial pathogens: epidemiology, taxonomy, typing methods, and pathogenicity factors. Clin Microbiol Rev. 1998;11(4): 589603. PMID: 9767057

20. Molaabaszadeh $\mathrm{H}$, Hajisheikhzadeh B, Mollazadeh M, Eslami K, Mohammadzadeh Gheshlaghi N. The study of sensibility and antimicrobial resistance in Escherichia coli isolated from urinary tract infection in Tabriz City. J Fasa Univ Med Sci. 2013;3(2):149-54. [Persian]

21. Keikha M, Rava M. Evaluation of antibiotic resistance of Escherichia coli strains isolated from urinary tract infections in outpatients referring to Nabi Akram Hospital in Zahedan. J Paramed Sci Rehabil. 2017;6(4):73-8. [Persian]

22. MohamadiMehr M, Faizabadi MM, Bahadori O. Antibiotic resistance patterns of gram-negative bacilli responsible for nosocomial infections in hospital intensive care department of family and Golestan Tehran 2007. J Army Univ Med Sci. 2010;8(4):283-90

23. Sharifi Yazdi M, Azarsa M, Shirazi M, Rastegar Lari A, Owlia P, Fallah Mehrabadi J, et al. The frequency of extended spectrum beta lactamase and CTX M-I of Escherichia Coli isolated from the urine tract infection of patients by phenotypic and PCR methods in the city of Khoy in Iran. $J$ Zanjan Univ Med Sci Health Serv. 2011;19(77):53-61. [Persian]

24. Barari SR, Pournasrollah M, Babazadeh N. Antibiotic resistance of bacteria causing urinary tract infections in children hospitalized in Amirkola children hospital during 2010-2011. J Babol Univ Med Sci. 2013;15(5):89-94. [Persian]

25. Ny S, Edquist P, Dumpis U, Gröndahl-Yli-Hannuksela K, Hermes J, Kling AM, et al. Antimicrobial resistance of Escherichia coli isolates from outpatient urinary tract infections in women in six European countries including Russia. J Glob Antimicrob Resist. 2019;17:25-34. PMID: 30447337 DOI: 10.1016/j.jgar.2018.11.004

26. Ramírez-Castillo FY, Moreno-Flores AC, Avelar-González FJ, Márquez-Díaz F, Harel J, Guerrero-Barrera AL. An evaluation of multidrug-resistant Escherichia coli isolates in urinary tract infections from Aguascalientes, Mexico: cross-sectional study. Ann Clin Microbiol Antimicrob. 2018;17(1):34. PMID: 30041652 DOI: 10.1186/s12941-018-0286-5

27. Dormanesh B, Mirnejad R, Khodaverdi Dariyan E, Momtaz H, Yahaghi E, Safarpour Dehkordi F, et al. Characterization and study the antibiotic resistance of uropathogenic Escherichia coli isolated from pediatrics with pyelonephritis and cystitis in Iran. Iran J Med Microbiol. 2013;7(2):27-39. [Persian]

28. Paknejad Z, Paknejad H, Tajbakhsh E. Determination of antibiotic resistance pattern in different serotypes of Klebsiella pneumoniae strains isolated from hospital infections in Zarinshahr. Sci Res Appl Biol. 2018;8(29):2130. [Persian]

29. Adamus-Białek W, Baraniak A, Wawszczak M, Głuszek S3, Gad B3, Wróbel K, et al. The genetic background of antibiotic resistance among clinical uropathogenic Escherichia coli strains. Mol Biol Rep. 2018;45(5):1055-65. PMID: 30008141 DOI: 10.1007/s11033-018-4254-0 